
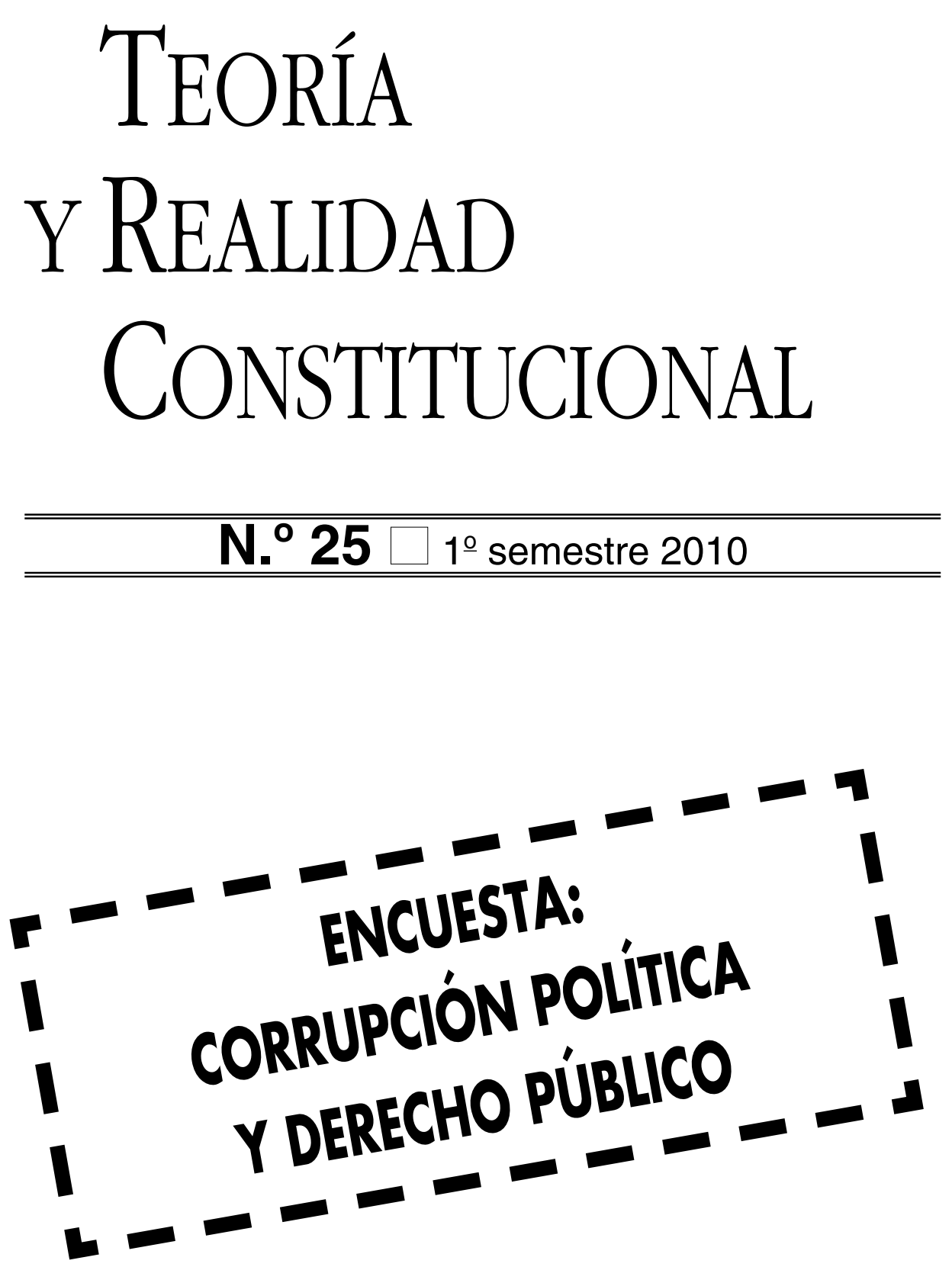


\title{
EL CONSENSO (DEL PROCESO CONSTITUYENTE A LAS PRÁCTICAS POSTCONSTITUCIONALES) ${ }^{1}$
}

\author{
ÓSCAR ALZAGA VILLAAMIL \\ Catedrático de Derecho Constitucional \\ Universidad Nacional de Educación a Distancia
}

Señores académicos:

Debo empezar por dejar constancia de mi gratitud a todos los miembros de esta Real Academia porque me hayan permitido acceder a la misma. Y especialmente a quienes presentaron mi candidatura, Srs. Sánchez Asiaín, Carrillo Salcedo y Lavilla Alsina. Por ser conocedor de mis escasos méritos, sólo puedo entender el presente trance como forma atípica de donación, con causa en la mera liberalidad de los donantes, quedando, en cuanto donatario, obligado a perenne gratitud, conforme a lo dispuesto en el artículo 468 del Código civil.

La plaza con que se me honra es de nueva creación, por lo que no sucedo a ningún Académico cuya semblanza pueda glosar. Pero deseo rendir tributo a mis maestros en la disciplina. Diversas constituciones, como la nuestra, permiten investigar la paternidad, pero aún nada dicen de una posible paternidad compartida. No obstante, soy discípulo de padres varios. Cuatro. Todos ellos académicos en su día de esta Corporación: D. Carlos Ruiz del Castillo, D. Luis Sánchez Agesta, D. Carlos Ollero y D. Francisco Murillo Ferrol. De su magisterio aprendí, junto a un rico bagaje de enseñanzas, a dar prioridad a una visión realista del Derecho constitucional sobre los deslumbrantes envoltorios del "refinadísimo juego convencional del positivismo lógico".

Tengo que expresar también mi gratitud por el testimonio de vida cívica que recibí de dos grandes universitarios, el Maestro de la Universidad de Sevilla, D. Manuel Giménez Fernández y el Profesor de Madrid, D. Joaquín Ruiz Giménez.

1 Texto de la intervención oral del autor en el acto solemne de su ingreso como académico de número en la Real Academia de Ciencias Morales y Políticas el 16 de marzo de 2010. El Discurso íntegro, junto con el de contestación, en nombre de la Corporación, del Académico D. Landelino Lavilla Alsina, está recogido en el libro editado por la propia Academia al efecto. 
Adentrándonos ya propiamente en este "Discurso" — que, según sostiene la Española, no es término sinónimo de monografía sino de reflexión- querría exponer, en primer lugar, cómo el consenso constitucional con su natural alcance y contenido, precisa de la virtud de la concordia y de la práctica del diálogo, para dar frutos constituyentes y para desarrollar en términos óptimos las más significativas prácticas aplicativas de la Constitución. En segundo término, verter alguna glosa sobre cómo esto se ha producido entre nosotros. Y, por último, decir algo sobre las brumas que entrevemos en el horizonte.

El consenso es para los españoles el sabio método, que apoyado en la virtud cívica de la concordia, alimentó nuestra "transición" por antonomasia y su obra, la Constitución política de 1978. Obviamente mis palabras no han de ser lo que denominó un día Marco Aurelio un "testamento de gratitud aguas arriba". Es innecesario porque de este esfuerzo decisivo, en el que tantos de los que estamos hoy aquí participamos, pervive un gran recuerdo en la memoria colectiva. Basten unas pinceladas para contextualizar el sentido de un torrente de voluntades convergentes, que tuvo su desembocadura en la obra del poder constituyente.

Una primera anotación es que se siguió un viejo camino que ya había dado grandes frutos a la civilización occidental. El del diálogo que busca grandes entendimientos en espíritu de concordia. Lo defendieron con buen tino en Grecia significativos filósofos, desde Aristóteles ${ }^{2}$, hasta los estoicos a la vista de la obra militar y política de un Alejandro Magno que buscaba el entendimiento entre pueblos que anteriormente se habían desconocido ${ }^{3}$. Se importa a Roma por Cicerón en plena guerra civil, al escribir sus diálogos sobre "La República ${ }^{4}$, donde sostiene que sin la concordia la colectividad ni es propiamente sociedad ni puede articularse en Estado. Y, como sabemos, Polibio nos legó un fino testimonio de cómo Roma decantó tal aspiración a una óptima convivencia política desde sus experiencias históricas 5 .

Es erróneo el tópico de que la tierra española no ha sido históricamente fértil para grandes diálogos y trascendentes consensos. Hay importantes hitos que jalonan caminos de entendimiento por los que avanzaron nuestros antepasados con mente clara y el mejor espíritu de concordia. Así en nuestra Baja Edad Media hubo grandes acuerdos jurídico políticos que resolvieron problemas especialmente delicados. Tal fue el caso en la Corona de Aragón de la Concordia de Alcañiz, de 1412, entre los Parlamentos de Aragón y Cataluña sobre el modo de designar Rey.

2 ARISTÓTELES: Ética a Nicómaco, IX, 6., págs. 146-147. Citamos por la traducción al español de Julián Marías, 9a ed. Ed. CEPYC, Madrid, 2009.

3 Cfr. BARKER, E.: From Alexander to Constantine: Paages and Documents illustrating the History of Social and Political Ideas. B.C.-A.D. 337, Oxford, 1956.

4 CICERÓN, M.T.: La República, años 54 a 51 a. de J. C., Libro II, Capítulo 42 y Libro III, Capítulo 31.

5 POLIBIO: Historia de Roma. Citamos por traducción española, Alianza Editorial, Madrid, 2.008. Libro VI, fragmento 10, pág. 586. 
O también de la Concordia de Villafranca del Penedés, de 1461, suscrita entre la Reina Juana, en nombre de su marido el Rey Juan II de Aragón, y la Junta del Principado de Cataluña ${ }^{6}$. Esta Concordia fue un monumento al pactismo y, al tiempo, la consagración de la primacía de las Cortes en ciertos ámbitos ${ }^{7}$ y un gran precedente de la reducción de la prerrogativa regia que se vive por las monarquías constitucionales tras la revolución inglesa del siglo XVII y la Francesa del siglo XVIII.

En Castilla, cuando Fernando el Católico pretendió, con nulo éxito, gobernar sólo este Reino, hubo de suscribir la célebre Concordia de Segovia, el 15 de enero de 1475. Prima facie puede extrañar que ello se produzca en aquel siglo XV, que asistía al alumbramiento de las monarquías absolutas en Europa. Pero la realidad era un tanto más compleja. Las élites renacentistas, en aquellos albores de la edad moderna, aspiraban a un renacimiento de la Edad de Oro, concebida como el reino de la concordia y de la armonía diseñado en la Polis y en la Civitas clásicas ${ }^{8}$. Era el ideal de una convivencia pacífica libre de tensiones, como dulces eran las formas y los colores de las pinturas de Rafael de Urbino.

Hay otros muchos ejemplos relevantes de magnos conciertos de voluntades que se fraguan en normas de Derecho público español en los siglos sucesivos; aunque ello no permite ocultar cuánto hay de confrontaciones radicales, durante nuestro convulso siglo XIX entre las llamadas Dos Españas. Pero tampoco entonces todo fue contienda ayuna de diálogo y carente de entendimientos y compromisos.

Así cabe recordar que de la pluma de D. Juan Valera emanaron en 1864 unos estudios sobre la política de su tiempo ${ }^{9}$, modelo de prosa pulcra y serena, puesta al servicio de la exaltación de los valores de la convivencia en libertad, huérfana de todo extremismo. En sus palabras se palpa una tradición española, viva aún en plena crisis socio política de nuestra historia decimonónica, que suele olvidarse en demasía y que debe ser reivindicada. Una tradición que a veces se nos aparece como crítica y defensiva, quizás porque a menudo ha tenido que conquistarse a base de esfuerzo el derecho a existir, porque se ha visto obligada a buscar el aire que respirar, el que tenía que hacer vibrar para hacer sonar en esta dura tierra nuestra unas cuantas palabras mesuradas y justas, unas pocas palabras verdaderas ${ }^{10}$.

6 Puede consultarse a este respecto el Discurso de "Elogio a la Concordia", que, con motivo de la entrega del Premio anual a la Concordia a D. Santiago Carrillo, pronunció D. Landelino Lavilla, en el acto público celebrado bajos los auspicios de la Fundación Fernando Abril Martorell.

7 Vid. AAVV: Manual de Historia del Derecho Español; Tomo II: "Antología de Fuentes del Antiguo Derecho", décima reimpresión, Madrid, 1984, número 1076, pág. 903.

8 En un Colegio Mayor de la Salamanca renacentista podemos leer el siguiente aserto, esculpido en la piedra dorada de esta ciudad universal: "La ira engendra el odio, la Concordia nutre el amor. Espíritus enconados no lograron nunca la Concordia, pero ésta retornará al benevolente el ciento por uno del esfuerzo que realiza".

9 VALERA, J.: Estudios críticos sobre literatura, política y costumbres de nuestros días, Ed. Librería de A. Durán, Madrid, 1864.

10 MARÍAS, J.: Los Españoles", Ed. Revista de Occidente, Madrid, 1962, pág. 127. 
A esa tradición alude el personaje de "La velada en Benicarló" al que Azaña hace decir: "Yo hablo de la tradición liberal y humanitaria española, porque (...) ha habido siempre un arroyuelo murmurante de gentes descontentas, del cual arroyuelo nosotros venimos y hemos convertido en ancho río ${ }^{11}$.

Ciertamente, el río torrencial que se desbordó en 1936 no provino de ningún manantial liberal ni de ningún afluente humanista. No hubo lugar para el consenso ni en el estallido de la guerra civil ni en sus amargas consecuencias.

Pero llegó una primavera de pretransición rica en esfuerzos cívicos por facilitar el diálogo de todos los españoles desde la filosofía de la libertad, y por fin florecieron la cultura cívica de la pretransición y la llamada transición ${ }^{12}$. El proceso estuvo tan plagado de dificultades como impregnado de un diálogo generoso que hacía suyos los versos de Antonio Machado: "Tu verdad no, la Verdad / Vamos juntos a buscarla / La tuya guárdatela".

$\mathrm{Al}$ analizar el consenso constituyente de 1977-1978 hay que ser realistas y cautos. No son asumibles la mayoría de las teorizaciones posteriores sobre el mismo, porque sus motivaciones no respondían a esquemas de seminario de Ciencia política. Ni hubo un movimiento pendular frente a la vieja máxima de Ferdinand Lasalle: "Nada de pactos" ${ }^{33}$; ni se trató de seguir con frialdad el modelo de la llamada democracia consociacional, recogido en la obra de Lijphart $^{14}$, ni de poner en práctica las interesantes ideas de científicos de la teoría económica de la política, como Buchanan y Tullock ${ }^{15}$.

El consenso en la España de 1977 / 1978 alcanzó la categoría de ideal, en el sentido en que para Sartori un ideal es algo que nace de una mala trayectoria - a saber, buena parte de nuestra tradición de constituciones impuestas o de partido - y que emerge de la insatisfacción ante una realidad - léase, la seudo unanimidad anterior- para encarnar una reacción ${ }^{16}$. En nuestro caso con la vista puesta en los mejores modelos constitucionales europeos, asumibles por todos los españoles.

En sede constituyente, un consenso, como se deduce de su etimología, no tenía que consistir en "aprobar", sino en aceptar y compartir con otros. Sobre lo que se tenía que producir un "sentir conjunto" era sobre una cultura política. Y la cultura política no tiene que configurarse, como algunos sostienen,

11 AZAÑA, Manuel: La velada de Benicarló, Ed. Losada, Buenos Aires, 1939, pág. 137. Vid., también: PAYNE, S. G: El colapso de la República. Los orígenes de la guerra civil (1933-1936), Traducción española, Ed. La Esfera, Madrid, 2.005, págs., entre otras, 527-532.

12 Vid. LAVILla ALSINA, L.: Politica de la memoria. Discurso de recepción pronunciado en la Real Academia de Ciencias Morales y Politicas el 12 de diciembre de 2006.

13 LASALLE, F.: ¿Qué es una Constitución? (Conferencia pronunciada en abril de 1862). Traducción española, Ed. Ariel, Barcelona, 1976, págs. 143 y 144.

14 LIJPHART, A.: De sus muchas publicaciones al respecto, véase, por todas: Democracies: Patterns of Majoritarian and Consensus Government in Twenty-One Countries, Ed. Yale University Press, New Haven, 1984.

15 BUCHANAN, J. M. y TULLOCK, G.: El cálculo del consenso (fundamentos lógicos de una democracia constitucional), Traducción española, Ed. Espasa-Calpe, 1980. 75 .

16 SARTORI, G.: ¿Qué es la democracia?, Traducción española, Ed. Taurus, Madrid, 2003, pág. 
por creencias específicas concretas. Basta con que se conforme en base a creencias difusas, como sostuvo acertadamente Almond ${ }^{17}$.

Un consenso constituyente debe abarcar varios terrenos: En primer lugar, sobre valores y principios; incluyendo valores generalmente aceptados y eludiendo valores polémicos. Y puede no ser completo. Cabe que una Constitución se asiente sobre una cultura cívica heterogénea, pero si contribuye a asentar una cultura cívica homogénea la democracia será más estable, con menos disensos.

En segundo término, el consenso debe abarcar la composición y el funcionamiento de los órganos de los poderes públicos, incluyendo un pacto completo sobre las reglas de juego.

En tercer término, aunque es factible algún consenso en sede constituyente sobre políticas de gobierno, este campo debe quedar abierto al juego político pluralista. Y es que como dijo Barker "la esencia de todas las democracias (reside en) gobernar discutiendo" ${ }^{18}$.

El consenso, por lo demás, facilita la elasticidad de la Constitución, y, de modo natural, margina las fórmulas que puedan hacerla inelástica. Aunque en Derecho constitucional no hay que confundir elasticidad con eternidad. Las reformas constitucionales son imprescindibles. También volveremos sobre esto.

Pues bien, toda Constitución fruto de un proceso constituyente debe desempeñar un papel esencial que, en palabras de Smend, describiremos como "sistema jurídico de integración", que en realidad implica una dialéctica espiritual, que no se agota en el acto de entrada en vigor de la Constitución ${ }^{19}$. Más bien, el Estado se renovará permanentemente mediante un complejo proceso integrador que se extiende a la propia Constitución indefectiblemente sumergida en su propia dinámica renovadora. Ello en gran parte se puede lograr a través de la legislación orgánica u ordinaria y, en otra medida, por medio de la actualización del texto constitucional.

Con razón, Robert Dahl expuso la necesidad de que las Constituciones contribuyan a que los líderes políticos desarrollen lo que denominó un "consenso informado sobre las leyes políticas, mediante compromisos que faciliten la conciliación de los diversos intereses ${ }^{20}$. Y estableció una interrelación entre la solidez de las democracias y la capacidad de sus dirigentes de adoptar periódicamente acuerdos por consenso. Pero escribió que el logro dependía de cinco condiciones: Primera, una identidad nacional que desaliente las exigencias de la separación directa. Segunda: Un compromiso constituyente

17 ALmOND, G. A. : Political Development: Essays in Heuristic Theory, Ed. Little Brown, Boston, 1970, especialmente Capítulo I.

18 BARKER, Ernest: Reflections on Government, Ed. Oxford University Press, Oxford, 1942, pág. 67.

19 SMEND, RUDOLF: Verfassung und Verfassungsrecht, Ed. München U. Leipzig, 1928. Traducción española: Constitución y Derecho constitucional, Ed. CEC, Madrid, 1986, págs. 62 y ss. 145 .

20 DAHL, Robert A.: La Denocracia, Traducción española, Ed. Taurus, Madrid, 1999, pág. 
amplio sobre valores y completo sobre los procedimientos democráticos. En tercer término: Cierto talento para la conciliación. Cuarta: Alta tolerancia para el compromiso. Y quinta: Líderes competentes y fiables que puedan negociar soluciones a los conflictos. Requisitos que hunden sus raíces en las páginas de la Ética a Nicómaco de Aristóteles, en El Federalista de Hamilton, Madison y Hay, o en diversos escritos de Stuart Mill. Y es que la politología contemporánea cuando reflexiona sobre el consenso conecta con una larga y fecunda tradición de la historia del pensamiento político.

Estos requisitos, en cuanto exigen que el consenso se extienda a un acuerdo completo sobre las bases de ordenación del poder y las reglas a que se debe atener su funcionamiento, ponen de manifiesto que en nuestra Constitución su Título VIII y su Estado de las Autonomías es más digno de elogio por el espíritu generoso que le impregna que por su oscuro perfil técnico jurídico, indefinible hibrido apertus, que, entre tantos ius publicistas, desespera a un jurista ecuánime como D. Álvaro Rodríguez Bereijo que lo definió en 2009 como "un marco consustancialmente conflictivo y permanentemente tensionado ${ }^{21}$ y que consecuentemente, pensamos nosotros, amenaza con asfixiar al propio Tribunal Constitucional.

Así el Título VIII se nos muestra en la carrera del consenso como la gran asignatura pendiente. Y ello en sentido estricto. Ya que nuestra Constitución demandaba en términos más o menos expresos consensos ulteriores a su entrada en vigor.

Ciertamente debe constatarse que todo el proceso de nuestra transición fue gradualista. En términos de Derecho positivo se inició, como mínimo, en la Ley para la Reforma Política que precede a las primeras Cortes fruto de unas elecciones libres, competitivas y rodeadas de las debidas garantías. Y durante el largo proceso constituyente se dan pasos hacia un nuevo Estado democrático, algunos tan relevantes como los que impulsaron las denominadas preautonomías. El gradualismo de todo el proceso está empapado de consenso. El consenso era el método que presidía un proceso que no se agotaría en fase constituyente.

Sin duda, la Constitución dejaba áreas significativas abiertas a consensos de futuro. El gradualismo se extendía así obviamente hacia adelante, delegando algunos aspectos del cierre de la transición y de la propia Constitución en la legislación orgánica. Consecuentemente pensamos que sólo se puede concebir el curso del tránsito político como alentado por nuevas dosis de consenso. Ésta creo que era también la visión del Profesor Aragón Reyes cuando en 1998 escribió: "Consenso no sólo como acuerdo entre las fuerzas políticas, sino también como pacto histórico, es decir, consenso tanto en sentido horizontal como vertical: Consenso en el presente, pero también consenso con el pasado y consenso exigido para el futuro (y no

21 RODRÍGUEZ BEREIJO, Á.:” La Constitución española en su XXX Aniversario", Conferencia pronunciada en la Universidad de Málaga el 22 de enero de 2.009, en Revista Española de Derecho Constitucional, núm. 86, mayo /agosto 2.009, págs. 11 y ss. 
sólo para el desarrollo de las autonomías y para la aplicación de las leyes orgánicas) ”22.

Fruto directo de esta exigencia de consenso para el futuro es que, aunque en el campo del Derecho constitucional comparado coexistan constituciones que prevén leyes orgánicas con otras que no lo hacen, la nuestra no sólo pertenece al primer capítulo sino que lo encabeza, al establecer reservas de ley orgánica para un alto número de supuestos. Motivación significativa — sin perjuicio de otras también dotadas de peso- fue el prolongar un cierto espíritu de consenso en materias trascendentes (tales como: Derechos fundamentales, instituciones básicas del Estado, régimen electoral y un largo etcétera), sobre las que se precisaba un desarrollo legislativo que demandase no la mera mayoría simple, sino la mayoría absoluta del Congreso $^{23}$, con su "plus de legitimidad".

A la par, en materia de reservas de ley ordinaria nuestra Constitución de 1978 también se ubica en lo más alto del respectivo ranking europeo. Creemos que ello no se debe sólo a la corriente histórica de lógica garantista que acompaña a las leyes votadas en $\operatorname{Cortes}^{24}$, ni al viejo recurso al "Principio democrático" para explicar la primacía de la Ley, obra de un Parlamento electo, sobre el Reglamento, producto de un Poder ejecutivo subordinado a aquel ${ }^{25}$. Trae causa, sobre todo, de la importancia que otorgan u otorgamos los constituyentes al hecho de que la Ley no sólo es votada, sino, sobre todo, discutida en las Cámaras. Es la vieja legitimación del diálogo que busca la comprensión recíproca de posiciones diversas, siguiendo la recomendación de Antonio Machado en un verso sabio: "Para dialogar / preguntad primero.../ después escuchar".

Si hay una sobredosis de reservas de ley en nuestra Constitución es por un trasunto de la filosofía del consenso. Las Cortes, como sede donde la representación alcanza su verdadero sentido escénico, son la casa de la deliberación; de los consensos y disensos entre Gobierno y oposición, con la máxima publicidad que garantiza la tribuna de prensa. Mientras que los reglamentos se gestan en el tan respetable como oscuro seno del vientre materno gubernamental, al que se accede previo juramento o promesa de guardar el secreto de las deliberaciones del Consejo de Ministros. Puede decirse que nuestra Constitución pretendió asegurar altas cotas de lo que hoy se llama democracia deliberativa. Naturalmente no me refiero a la corriente doctrinal utópica de la democracia deliberativa que busca suprimir los órganos

22 ARAGÓN REYES, M.: Estudios de Derecho constitucional, Ed. CEPYC, Madrid, 1998, págs. 33 a 36.

23 Vid. AlZAGA VILLAAMIL, Ó.: "En torno al concepto de Ley Orgánica en la Constitución", en Teoría y Realidad Constitucional, núm. 5, Primer semestre 2.000, págs. 140 y ss.

24 GARRORENA MORALES, Á.: El lugar de la ley en la Constitución española, Ed. CEC, Madrid, 1980, ver especialmente págs. 61 y concordantes.

25 Vid. OTTO, I. de: Derecho constitucional. Sistema de fuentes. Ed. Ariel, Barcelona, 1987, págs. 135 y concordantes. 
colegiados representativos mediante vías de democracia directa ${ }^{26}$. Aludo a la corriente realista de la democracia deliberativa que propugna potenciarla esencialmente en el Parlamento. Es el idealismo democrático contemporáneo, difícil de alcanzar, pero que piensa lograble que la elaboración de la Ley surja en la "situación ideal de diálogo", siga el curso de lo que en palabras de Braybrooke llamaríamos un "debate lógicamente completo" — que estaría en la práctica sólo limitado por lo que Dahl denomina «el tiempo que permite la necesidad de decidir" ${ }^{27}$ y culmine esencialmente por "la fuerza del mejor argumento", como gustó en decir Jürgen Habermas ${ }^{28}$.

No puedo ahora adentrarme en los límites y restricciones con que tropieza en la práctica el ideal deliberativo, a los que han dedicado su atención estudiosos como John Rawls o James Fishkin, o sobre el viejo problema de la necesaria cualificación de los legisladores, que quitó el sueño a Stuart Mill. El ideal utópico platónico y a la vez la eterna sensibilidad hacia el nivel de capacidad de los hombres a los que se confía el debate y la gestión de la cosa pública.

Pero, en nuestro tiempo la vieja preocupación por la capacidad en el uso de la palabra, se ve desplazada por la primacía de la imagen y las técnicas de la puesta en escena de lo político. Como ha sostenido el Prof. Marchán, "asistimos a un cambio de la cultura política logocéntrica por una iconografía en que la estética de la presencia es decisiva «" ${ }^{29}$. Pero reconociendo cuanto de gran verdad hay en ello, continua siendo necesario en materias capitales buscar consensos entre las posiciones políticas enfrentadas. Aunque una vez logrados se escenifiquen no con la mejor retórica parlamentaria sino con la más cuidada estética en la comparecencia ante los medios.

De otro lado, nuestra Constitución proyecta sus demandas de consensos futuros para resolver la composición de los grandes órganos constitucionales, entendiendo por ellos, en palabras de García Pelayo, los que "son propios (a cada estructura constitucional), necessari e indefettibili, cuya desaparición afectaría a la sustancialidad y, con ello, a la globalidad del sistema constitucional ${ }^{30}$. Como tales emergen al menos dos: El Tribunal Constitucional y el Consejo General del Poder Judicial. Y probablemente algún otro, como par-

26 Vid. MORENO RODRÍGUEZ ALCALÁ, D.: "Una aproximación a la concepción deliberativa de la democracia", en Teoría y Realidad Constitucional, núm. 16, segundo semestre de 2.005, págs. 313 y ss.

27 DAHL, R.: "Procedural Democracy”, en LASLETT, P. y FISKIN, J. (Editores): Philosophy, Politics and Society, Ed. Yale University Press, New Haven, 1979, Vol. V, págs. 105 a 107.

28 HABERMAS, Jürgen: "A Reply to my critics, en Thompson, J. B. y HELD, D. (Editores): Habermas: Critical Debates, Ed. MIT Press, Cambridge, 1982, págs. 219 y ss. Vid., también, HABERMAS, J.: "El vínculo interno entre Estado y democracia”, en el compendio de trabajos del mismo autor: La inclusión del otro, Traducción española, Ed. Paidos, Barcelona, 1999, especialmente, págs. 231 a 246.

29 MARCHÁN FIZ, S.: La estética ético política en la modernidad y después...Ed. UNED, Madrid, 2009, pág. 58.

30 GARCÍA PELAYO, M.: "El status del Tribunal Constitucional", en Revista Española de Derecho Constitucional, núm. 1, año 1981, págs. 14 y 15. 
ticularmente el Tribunal de Cuentas. La composición de esta suerte de órganos, a diferencia de la del Parlamento o de la del Gobierno, debe resolverse mediante acuerdos que solventen el peligro de la dependencia partidista de sus miembros ${ }^{31}$.

Por último la Constitución del 78 demanda consensos de futuro para ir adecuándose a la realidad social cambiante y así asegurar su permanente lozanía. La idea de las constituciones sempiternas - que tiene en nuestra tierra un precedente en la ley perpetua de los comuneros castellanos- nunca pasó de ser, en los siglos XVIII y XIX, un ideal de revolucionarios huérfanos de realismo, incursos, en ocasiones, en el extendido pecado de la vanidad legislativa. Pero los constituyentes de nuestra Carta Magna éramos plenamente conscientes de que la misma incluía órganos, instituciones y procedimientos plasmados en una Constitución por primera vez en nuestra historia. Faltos de experiencia, actuábamos in vitro.

Es cierto que el Título X de la Constitución instaura para la reforma total o para una parcial que afecte a especiales parcelas, una vía dotada de los mecanismos de super-rigidez, establecidos en el artículo 168 de la Constitución, ampliamente criticados por buena parte de los especialistas y sobre los que no nos detendremos. Pero no es menor verdad que los constituyentes, con la debida modestia, partimos de que el curso de la práctica política pondría de manifiesto ajustes necesarios a abordar, mediante el pertinente consenso, a través del transitable camino de reforma ordinaria de la Constitución regulado en su artículo 167 . Uno de los de más accesible andadura de cuantos muestra el constitucionalismo europeo. Y es que, como ha afirmado el prof. Rubio Llorente "sólo una Constitución reformable es democráticamente legítima ${ }^{32}$. Y en la Europa de 1978 las grandes democracias, Alemania, Francia, Italia, Suecia y todas las demás, ajustaban periódicamente sus respectivas constituciones, vía reformas. Con realismo en los estados de la Unión Europea se asume que sólo los libros sagrados se han escrito para permanecer inmutables en el tiempo.

Veamos ahora cómo se empezaron a atender estas demandas constitucionales de consensos futuros. Sobre ello puedo declarar en estrados en calidad de testigo ya que desde el inicio de la primera legislatura - marzo de 1979_- declinando otras responsabilidades, asumí ser portavoz de UCD en la Comisión constitucional del Congreso y, poco después, presidí simultáneamente la Comisión de Justicia e Interior, coordinando una parte significativa del quehacer del primer legislador orgánico.

31 Esta es una cuestión clásica en Derecho constitucional. Vid., por ejemplo, CRISAFULLI, V.: "La Corte costituzionale tra magistratura e parlamento", en Scritti in memoria di Calamandrei, Padova, 1958, Vol. IV, págs. 273 y ss.; BARILE, P.: "La Corte costituzionale órgano sovrano, implicazione pratiche", en Giur. Cost., año 1957, págs. 907 y ss.; y VERGOTTINI, G. de: Diritto costituzionale, Ed. CEDAM, Padova, $3^{\text {a }}$ ed., 2.001, págs. 612 a 614.

32 RUBIO LLORENTE, F.: "La reforma de la Constitución. Sobre la posibilidad, conveniencia y dificultad de llevarla a cabo", en Claves de razón práctica, núm. 188, diciembre de 2.008, pág. 6. 
Por entonces se debatieron y acordaron una multitud de leyes orgánicas que, bien recogían formalmente los Estatutos de Autonomía, bien regulaban el desarrollo de los derechos fundamentales y de las libertades públicas, o bien estaban llamadas a regir la composición y el funcionamiento de los grandes órganos e instituciones capitales. Es de justicia levantar acta de que en aquella primera legislatura los grandes partidos estuvieron casi siempre -incómodas, y algunas graves, excepciones al margen- a la altura del requerimiento que les hacía nuestra primera Ley para cerrar ambos por consenso la obra constituyente. Y puede añadirse que cuando las circunstancias lo aconsejaban y permitían se buscó extender el consenso a los partidos nacionalistas, en lo que hoy se denomina nuestro "sistema multinivel" de parti$\operatorname{dos}^{33}$ y que academicamente puede analizarse desde la óptica de Lipset y Rokkan: Un sistema de partidos bidimensional, que incluye los de índole nacionalista y representable mediante dos curvas que se entrecruzan, en un eje de abscisas ${ }^{34}$.

Sin embargo entre aquellos esfuerzos por consensuar en la primera legislatura grandes leyes orgánicas, hubo algún caso en que, por exceso de consenso, se pecó de inconstitucionalidad. Mencionaré dos ejemplos:

El primero lo viví, en 1980, como Presidente de la Comisión de Justicia e Interior del Congreso. Semanalmente acudía a unas reuniones con el equipo directivo del Ministerio del Interior, presididas por su titular, D. Juan José Rosón. Entre las ideas sobre medidas legislativas contra el terrorismo algunas eran muy particulares, como las extensiones de los supuestos de delitos flagrantes a otros diversos - por vía de pretendida analogía- para obviar la previa autorización judicial para la actuación policial respecto de los inviolables domicilios o las comunicaciones postales.

En sucesivas reuniones me opuse al intento por su inconstitucionalidad. Altos cargos del Ministerio contra argumentaban, ante el atento silencio del Ministro, que habían alcanzado un consenso suficiente "ad hoc" con el principal partido de la oposición. Ante la férrea terquedad de mis deformaciones de joven constitucionalista se creó una incómoda situación, de la que nos sacó el Ministro con la afirmación galaica de que todos estábamos en nuestro papel. A lo que añadió socarronamente que en su condición de modesto alumno de las largas clases que yo había impartido en aquel "aula" (sic) él había quedado preocupado porque se temía que podía llevar razón.

Aquellas ocurrencias se archivaron y tiempo después los propios tecnócratas del Departamento se las ofrecieron como bálsamo de fierabrás al Ministro Sr. Corcuera, quien las acogió con entusiasmo para aprobar la LO 1/1992, de 21 de febrero, sobre protección ciudadana (en terminología periodística: "Ley de pata-

33 Por ejemplo, LAGO, I. y MONTERO, J. R. : “Coordinación entre arenas electorales en países con sistemas políticos multinivel", en Revista de Estudios Políticos, núm. 140, abril-junio 2.008 , págs. 33 y ss.

34 LIPSET, S. M., y ROKKAN, S.: "Cleavage Structures, Party Sistems" en S.M. LIPSET - S. ROKKAN: Party Systems and Vote Alignments, 1967. 
da en la puerta"), anulada por la Sentencia del Tribunal Constitucional 341/1993.

Otro exceso en la gestación de un consenso inconstitucional, ajeno a la tensión a que estaba sometido Interior por la lucha antiterrorista, lo viví en 1981 como portavoz de UCD en la Comisión de Asuntos Constitucionales. En las alturas del Gobierno se había descubierto un atajo para resolver mediante unos breves párrafos los problemas del Estado autonómico y se había alcanzado un acuerdo con el principal partido de la oposición. Elevé, sin el menor éxito, mis argumentos sobre porqué era inconstitucional el Proyecto de la llamada "Ley Orgánica de Armonización del Proceso AutonómiCO" (LOAPA) ${ }^{35}$. Se me adujo que me dejase de exquisiteces constitucionales y asumiese que el proyecto estaba ampliamente consensuado. Comprendí que no eran tiempos para un constitucionalista de corta imaginación y dimití. La ley murió poco después de aquella sobredosis de consenso. El Tribunal Constitucional ${ }^{36}$ declaró que no podía tener carácter de ley orgánica, ni condición de ley armonizadora y declaró inconstitucional todas las partes significativas de su contenido dispositivo, incluyendo hasta el título de la ley. Había sobrado consenso, pero faltado el suficiente para seguir el único camino técnico jurídico transitable al efecto: El de la reforma constitucional.

Cambiando el tercio, de las leyes orgánicas a las ordinarias, constataré telegráficamente que por entonces estas se elaboraron en un clima de libertad, anchura y calidad de los debates, sin rodillos ni cortapisas ortopédicas.

Pero al glosar la práctica del consenso en la primera legislatura hay que subrayar la forma en que se plasmó un acuerdo impecable para el nombramiento de los componentes del primer Tribunal Constitucional. Gobierno y Oposición optaron por consensuar la totalidad de los magistrados, incluyendo los dos cuya designación correspondía al Gobierno, y logrando un Tribunal con juristas del máximo prestigio y competencia ${ }^{37}$. Y empapados de inde-

35 Aprobada con fecha 30 de junio de 1982.

36 STC 76/1983, de 5 de agosto. Que prácticamente aceptó por entero los recursos de inconstitucionalidad interpuestos por el Gobierno Vasco y por la Generalitat de Cataluña. Declaró la nulidad de 14 de sus 38 artículos.

37 Así el Congreso de los Diputados eligió a D. Manuel Díez de Velasco, D. Aurelio Menéndes, D. Francisco Rubio Llorente, y a D. Francisco Tomás y Valiente. El Senado eligió a Da Gloria Begué, D. Luis Díez Picazo, D. Manuel García Pelayo y D. Ángel Latorre, todos ellos — como es notorio- Catedráticos de diferentes Facultades de Derecho de nuestras Universidades de la época. Tras la pronta dimisión de D. Aurelio Menéndez, el Congreso de los Diputados eligió a D. Antonio Truyol, también Catedrático de Universidad. Por su parte, el Gobierno designó a D. Rafael Gómez-Ferrer y a D. Jerónimo Arozamena, el primero Catedrático y el segundo Magistrado. Seguidamente, el Consejo General del Poder Judicial eligió a D. Ángel Escudero y a D. Plácido Fernández Viagas, naturalmente ambos de la carrera judicial. En cuanto a la elección de estos dos últimos Magistrados por el CGPJ ciertamente hubo consenso pleno, pero enteramente ajeno a la dinámica política. RRDD 301/1980, de 14 de febrero. BOE, núm. 46 de 22 de febrero, págs. 4160 y 4161, con los nombramientos de los miembros del Tribunal Constitucional propuestos por el Congreso de los Diputados, el Senado y el Gobierno. RRDD 2514 y 2515/1980, de 7 de noviembre. BOE núm. 278, de 19 de noviembre, pág. 25855, con el nombramiento de los dos Magistrados propuestos por el Consejo General del Poder Judicial. 
pendencia. De forma análoga se alcanzó el mejor consenso para la primera composición del Consejo General del Poder Judicial.

Pero, sería gran ingenuidad pensar que la Constitución del 78 había conquistado nuestra convivencia política para siempre. En palabras de un prestigioso humanista "El éxito nunca es definitivo".

Y así, poco después, los requerimientos de consenso en torno a las leyes orgánicas fueron considerados meras barricadas de papel desbordables por una lucha política que buscó rentabilizar las virtudes electorales que pudieran concurrir en unas leyes cualificadas, que se produjeron después en mayor número durante el último año de cada legislatura, de ordinario aunándose el Gobierno con algún pequeño partido frente a la oposición mayoritaria. Mientras, para las leyes ordinarias el procedimiento legislativo se ha ido menguando, al partirse de la premisa de que los debates en profundidad son un lujo inútil a evitar.

En los nombramientos de Magistrados del Tribunal Constitucional y de los miembros del Consejo General de Poder Judicial, el consenso, como eje de las renovaciones, ha sido sustituido en gran medida por la lotización. Discutible práctica viciosa con precedentes en la política italiana y alemana, aunque en nuestros lares hemos logrado potenciarla hasta cotas insuperables. Hoy la dificultad del nombramiento de miembros sustitutos preside la dinámica abierta por toda vacante. La prorrogatio ha perdido carácter de excepcionalidad y nos ha ofrecido, por cierto, un excelente consuelo a los expertos propiciando un debate con andanadas de alta escuela entre los profesores, Santamaría Pastor y Aguiar de Luque ${ }^{38}$.

A lo anterior añadamos la notoria incapacidad que padecemos para reformar una Constitución con más de treinta años de vigencia, más allá del puntual retoque en 1992 de dos palabras de su artículo 13, por su obvia incompatibilidad con el $8^{\circ}$ del Tratado de Maastricht. Pero lo significativo de aquel momento radicó en el esfuerzo de nuestra élite política por no abrir un debate sobre la pertinencia de adaptar nuestra Constitución a los progresos de la integración europea. En la mayor parte de los países miembros de la Unión, con Alemania y Francia al frente, se había abierto un gran diálogo sobre la adaptación de las constituciones nacionales al nuevo marco europeo, por las transferencias de nuevas competencias a Bruselas, y por la pérdida de competencias sobre política monetaria y la desaparición de las respectivas monedas nacionales. Importantes estados miembros afrontaron reformas constitucionales de alcance ${ }^{39}$, pero nosotros eludimos todo diálogo sobre es-

38 SANTAMARÍA PASTOR, J. A.: "La prorrogatio de los órganos constitucionales. Apuntes mínimos sobre un tema que no lo es", en Revista Española de Derecho Constitucional, núm. 84, septiembre-diciembre 2.008, págs. 11 y ss. AGUIAR DE LUQUE, L.: "Una nueva reflexión sobre la prorrogatio de los órganos constitucionales. Una discrepancia y algunas puntualizaciones a J. A Santamaría", en Revista Española de Derecho Constitucional, núm. 85, año 2.009, págs. 83 y ss.

39 Vid. ARAGÓN REYES, M.: "La Constitución española y el Tratado de la Unión Europea", en Revista Española de Derecho Constitucional, núm. 42, año 1994, págs. 9 y ss. También, LÓPEZ AGUILAR, J. F.: "Maastricht y la problemática de la reforma constitucional", en Revista Española de 
tas cuestiones, quizás porque se había perdido la esperanza de engendrar nuevos consensos constitucionales. Y ello pese a que en nuestra Europa democrática es un axioma que la actualización y lozanía de una Constitución refuerza su legitimidad.

Así la Constitución belga de 1831, tras casi un centenar de reformas, fue objeto de un texto refundido en 1994, que ya ha conocido nuevas reformas. La Constitución austriaca de 1929 se ha modificado en unas setenta ocasiones. Las reformas y los intentos de reforma "non natos" de la Constitución italiana de 1947 son casi innumerables. La Constitución francesa de 1958 ha superado ya la veintena de reformas. Pero quizás la Constitución europea con mayor aureola entre los constitucionalistas españoles sea la alemana Ley Fundamental de Bonn de 1949, modelo de norma permanentemente mejorada. Ha sido objeto de revisión en cincuenta y siete ocasiones, terminando el cómputo en la de 29 de julio de 2009, última aprobada en los momentos en que entregamos a la Academia este Discurso.

Pero nuestra Constitución de 1978 lleva más de treinta años sin ser objeto de un esfuerzo de mejora. Es demasiado tiempo "sin pensar en grande", para decirlo en palabras de D. José Ortega. Y es el único caso de tal pasividad que se observa en el ancho campo de las grandes democracias europeas, porque la actual Grecia — que es, en esto, la única excepción de petrificación constitucional similar a la nuestra - no parece ostentar tal condición. Cuestión esta grave: La capacidad de las democracias para modernizar sus constituciones, solventando disfuncionalidades, está estrechamente correlacionada con la capacidad de consenso entre sus partidos y, en suma, con la calidad de su sistema político.

Y cuando se obstruye el cauce de la reforma constitucional, la búsqueda de nuevas soluciones discurre por regueros de facto hacia la jurisdicción del Tribunal Constitucional. Lo que supone otorgar al Tribunal Constitucional, no ya una potestad meramente nomofiláctica, sino nomotética ${ }^{40}$, con riesgo de la buena salud de la institución.

Quizás quepa preguntarse tanto por las dificultades para nuevos consensos, como por la profundidad real del vivido en el propio proceso constituyente, que pudo albergar facetas de mero modus vivendi constitucional, en la terminología de Rawls ${ }^{41}$. En suma, es la duda — sólo la duda- sobre si nuestro consenso de post contienda civil fue tan profundo como el logrado por los

Derecho Constitucional, núm. 38, año 1993, págs. 143 y ss; PÉREZ TREMPS, P.: “Las condiciones constitucionales al proceso de ratificación al Tratado de Maastricht en el Derecho Comparado", en Revista de la Facultad de Derecho de la Universidad Complutense, núm. 18, año 1994. Así como WEBER, A.: «El control del Tratado de Maastricht por la jurisdicción constitucional desde una perspectiva comparada", en Revista Española de Derecho Constitucional, núm. 45, año 1995, págs. 31 y ss.

40 Vid. PUNSET, R.: "Prólogo" a ÁLVAREZ ÁLVAREZ, L.: La lealtad constitucional en la Constitución Española de 1978, Ed. CEPYC, Madrid, 2.008, pág. XVI.

41 Vid. RAWLS, John. El liberalismo politico, Traducción española, Ed. Crítica, Barcelona, 2.006, págs. 190 y ss. 
norteamericanos tras su guerra de secesión, o el alcanzado por los alemanes tras su derrota en todos los frentes hasta ofrecer hoy un modelo envidiable de pluralismo razonable, que renueva permanentemente su consenso constituyente, sin cansancio. Como sostuvo Pascal: "Estaríamos hastiados de comer y de beber, si el hambre y la sed no se renovaran cada día".

Es necesario esforzarse por superar el impulso de los extremismos, que conducen hacia el radicalismo y los enfrentamientos en espiral de resultados imprevisibles. El diálogo debe sustituir tal impulso hacia la confrontación total, por un impulso alternativo de moderación y búsqueda de posiciones de encuentro.

Es verdad que la moderna politología puede definirse como una teoría del disenso; incluso como una teoría de las borrascas y de las tormentas. Es decir, una sturmlebre, que dijera Jacob Burckhardt. Pues las sociedades sin disensos más que utópicas son imposibles ${ }^{42}$. Pero diferenciemos el disenso razonable del conflicto radical. En la sociedad actual de anchas clases medias y menor distancia entre las actitudes de los electores, la confrontación política puede consistir bien en acortar distancias con los electores situados en la zona fronteriza entre los partidos, lo que facilita lo que en los años cincuenta del Siglo XX en Gran Bretaña se llamó "el consenso butskellista» ${ }^{43}$, bien en la descalificación in radice del adversario, mediante una campaña negativa que niegue su capacidad de gobierno y/o su honradez. Mediante esta descalificación total no se pretende captar electores moderados y dubitativos en su voto, sino llevar a la abstención a electores próximos al partido adverso, descrito como impotable.

Esta segunda opción puede abrir abismos en el seno de una nación, pero no faltarán intelectuales orgánicos que defiendan la progresiva crispación como exigencia del pluralismo político y del derecho a defender por todos los medios la propia ideología. Creemos que está constitucionalizado el pluralismo razonable ${ }^{44}$; no el pluralismo radical que practica una crítica sistemática de los adversarios, a los que sin pararse a pensar se trata como enemigos. Respetemos las ideas y los ideales generosos. Pero a las ideologías acerquémonos con cierta prevención ${ }^{45}$.

Las ideas, para ser tales, son fruto de la acción de pensar. Pero las ideologías políticas son ideas y creencias tenidas por ciertas por quienes no las

42 MOSCOVICI, Serge: La societé contre Nature, París, 1.972, pág. 84. Vid., también, NICHOLSON, Michael. Análisis del conflicto, Ed. IEP, Madrid, 1974.

43 El término lo acuñó The Economist para referirse a la proximidad existente entre la política económica y tributaria practicada por Hugh Gaitskell, Canciller del Exchequer en el Gabinete presidido por el Premier laborista, Clement Attlee, y la análoga política seguida por Richard A. Butler, también Canciller del Exchequer bajo el liderazgo del Primer Ministro conservador Winston Churchill.

44 Por decirlo en el léxico de Rawls. Vid. RAWLS, J.: El liberalismo político, Traducción española, Ed. Crítica, Barcelona, 2.006, págs. 194 y ss.

45 Vid. HEAD, B. W.: Ideology and Social Science, Destutt de Tracy and French Liberalism, Dordrecht, 1985. También, BELL, D.: The end of ideology, New York, 1962. Hay traducción española: El fin de las ideologías, Ed. Ministerio de Trabajo y Seguridad Social, Madrid, 1.992. 
han pensado y cumplen la función de economizar el esfuerzo de pensar. Las ideologías son pensamiento simplificado para la movilización y manipulación de las masas a las que alimentan de cierto instinto agresivo, que se cree respetable. Y que se caracteriza por no albergar ningún sentimiento de culpa individual, que recae siempre en "los otros". Tales ideologías pueden construirse no para "mentes abiertas", sino para "mentes cerradas", en la expresión de Rokeach ${ }^{46}$ y a la cerrazón contribuirán a diario los medios de comunicación que se hayan convertido en epifenómenos de los respectivos partidos.

Como ha sostenido Merton, en nombre de las ideologías se desemboca en un dogmatismo reforzado y en un nibilismo intelectual ${ }^{47}$. Y si los dirigentes de los partidos optan por la adhesión a ideologías cuyos distintivos centrales son excluyentes de los que sostiene la ideología del partido adverso, los militantes serán más radicales que los electores. Convencidos de que están en posesión de la verdad serán refractarios al diálogo y las respectivas tesis no serán reconciliables.

El contrapunto lo ofrecen los sistemas políticos con democracias avanzadas, con partidos no tributarios de simplismos ideológicos y con convicciones aptas para la convergencia con las de otros partidos, para amalgamar objetivos y desplegar esfuerzos de cooperación.

La ausencia de un clima de consenso conlleva males para una sociedad que los constitucionalistas no podemos solventar con las herramientas que nos proporciona la ingeniería constitucional. Así quedó claro en el deterioro del sistema político de Weimar y en la doctrina constitucionalista italiana de la segunda post guerra, que estudió a fondo la enfermedad de la radicalización política progresiva.

La clave de la óptima convivencia democrática está en el elemento volitivo, como comprendieron con agudeza Renan ${ }^{48}$, Mommsen $^{49}$ o nuestro Ortega, quien se preguntó “¿Tendrá (España) la voluntad de rehacerse?", y se contesta "Yo no lo sé " $"$. Sin duda todo depende de la capacidad de concordia. Porque concordar - como dijo Covarrubias - es componer voluntades discordes. Y, como bien decía D. Ramón Menéndez-Pidal: "La voluntad lo puede

46 ROKEACH: The Open and Closed Mind, Ed. Basic Books, págs. 39-51. Vid., también: FESTINGER, L.: A Theory of Cognitive Disonance, Ed. Stanford University Press, Stanford, 1957. Hay traducción española: Teoría de la disonancia cognitiva, Ed. Instituto de Estudios Políticos, Madrid, 1975. Y SARTORI, Giovanni: Elementos de Teoría Política, Ed. Alianza Universidad, Madrid, 1992, págs. 101 y ss.

47 MERTON, R.K.: Teoría y estructuras sociales, 1957, traducción española, Ed. Fondo de Cultura Económica, México, 1.992, pág. 503.

48 RENAN, E.: ¿Qu'estce qu une nation?, París, 1882. Recopilado este texto por primera vez en Discours et conférences, París, 1897, págs. 26 y ss. Hay múltiples traducciones españolas, entre las que cabe destacar: IEP, Madrid, 1957; CEC, Madrid, 1983 y Alianza Editorial, Madrid, 1987.

49 MOMMSEN, Th.: Historia de Roma, 1855-1856. Citamos por la traducción española de Ed. Aguilar, Madrid, 1962, Vol. I, págs. 21 y ss.; 563 y concordantes.

50 ORTEGA Y GASSET, J.: España invertebrada, Madrid, 1921. Citamos por la $5^{\mathrm{a}}$ ed. Ed. Revista de Occidente, Madrid, 1946, pág.118. 
todo, es decir, todo lo que sólo depende de nosotros mismos ${ }^{51}$. De aquí que, desde el espíritu constitucional, sería reconfortante que unos y otros hombres públicos en la aplicación cotidiana de nuestra Constitución, conscientes de que su preámbulo proclama "la convivencia democrática" como primer objetivo de la voluntad constituyente y superando reticencias personales, se acercasen a sus adversarios para decirles, en palabras de Pérez de Ayala: "Aquí estoy, contra mi voluntad y por mi voluntad, 52 .

Nada más. Muchas gracias por su atención.

TITLE: "Consenso" (from the constituent process to the postconstitutional practices).

ABSTRACT: The author analyses the evolution of the consensus during the first and the following terms of the legislature and finally shows his uneasiness concerning the prevalence of disagreements without dialogue.

Resumen: Analiza como ha evolucionado el consenso en la primera y posteriores legislaturas $y$ finalmente muestra sus inquietudes ante la prevalencia de discursos sin diálogo.

Palabras clave: Diálogo. Concordancia. Consenso constituyente. Leyes Orgánicas. Leyes Ordinarias. Reforma constitucional. Pluralismo radical. Pluralismo moderado. Ideologías. Radicalismo político.

Key Words: Dialogue. Concord. Constituent consensus. Constitucional Laws. Laws. Reform of the Constitution. Radical pluralism. Moderate pluralism. Ideologies. Political radicalism.

51 MENÉNDEZ-PIDAL, R.: En revista: Papeles de Son Armadans, núm. XXXIX, año 1959, pág. 26.

52 PÉREZ DE AYALA, R.: Los trabajos de Urbano y Simona, Plenilunio, Madrid, 1923. 